\title{
Association between somatic amplification, anxiety, depression, stress and migraine
}

\author{
Burcu Goksan Yavuz ${ }^{1 *}$, Elif Ilgaz Aydinlar², Pinar Yalinay Dikmen² and Cem Incesu ${ }^{1}$
}

\begin{abstract}
Background: The aim of this study is to investigate the associations between migraine related disability and somatosensory amplification, depression, anxiety, and stress.

Method: Fifty-five migraine patients who applied to the outpatient unit of the Neurology Department of Acibadem University School of Medicine, Maslak Hospital in Istanbul, Turkey, and twenty-eight subjects without migraine were recruited for the study. The participants were asked to complete a sociodemographic form, Migraine Disability Assessment Scale (MIDAS), Depression Anxiety Stress Scale, Somatosensory Amplification Scale (SSAS).

Results: Somatosensory amplification scores were significantly higher in the migraineurs than in the control group (29.85+/-6.63 vs $26.07+/-7.1 ; p=0.027)$. Somatosensory amplification scores and depression scores were significantly higher in migraineurs with moderate and severe disability than in patients with minimal and mild disability (31.7+/-6.4 vs $27.71+/-5.49 ; p=0.01,11.27+/-8.7$ vs $7.38+/-8.11 ; p=0.04$, respectively). A significant positive correlation was found between the frequency of migraine attacks for at least three consecutive months (MIDAS A scores) and the SSAS scores $(r=0.363, p=0.007)$ in migraineurs. The MIDAS total scores were also significantly correlated with the DASS depression subcale scores $(r=0.267, p=0.04)$, and the DASS stress subscale scores $(r=0.268, p=0.05)$.

Conclusion: Psychological factors, and vulnerability to bodily sensations may incease the burden of migraine. We point out that the timely assessing of somatic amplification and the evaluation of mental status would help improve the quality of life of in migraineurs.
\end{abstract}

Keywords: Migraine, Somatosensory amplification, Migraine disability, Depression, Anxiety, Stress

\section{Background}

Migraine, which is one of the leading neurological reasons for seeking medical care [1], is considered a chronic, disabling disease that significantly reduces quality of life $[2,3]$. The global prevalence of the adult members of the population with an active headache disorder are $46 \%$ for headache in general, $11 \%$ for migraine, $42 \%$ for tensiontype headache and $3 \%$ for chronic daily headache [4]. In a nationwide epidemiological study in Turkey, the lifetime prevalence of migraine was found to be $10.9 \%$ in men and $21.8 \%$ in women [5].

Migraine has been reported to be associated with various well-known comorbidities [6]- conditions which occur in people with migraine with greater chance of frequency than in others [7]. Several studies suggest that mood and

\footnotetext{
* Correspondence: burcugoksan@gmail.com

${ }^{1}$ Department of Psychiatry, Acibadem University School of Medicine, Istanbul, Turkey

Full list of author information is available at the end of the article
}

anxiety disorders are two to ten times more prevalent among people with migraine than in the general population, and greater than $25 \%$ of migraineurs meet the criteria for mood and anxiety disorders [8-10]. Population based studies demonstrate that depression is comorbid with migraine [11,12]. Major depression has been diagnosed in $40.7 \%$ of those with migraine and $16 \%$ of those in the control group [11]. In a study conducted by Lipton et al., $47 \%$ of migraineurs had depression while $17 \%$ of respondents in the nonmigraine group met the depression criteria, according to the Primary Care Evaluation of Mental Disorders screening questionnaire [12]. Other epidemiological studies have found that the lifetime prevalence of depression in migraine ranged from $17 \%$ to $42 \%$ [13-16]. A population-based study conducted by Chen et al. showed that $16 \%$ of the chronic migraine sufferers had anxiety disorders [17]. Breslau's population based prospective study shows that $24.4 \%$ of the migraineurs suffered from anxiety

\section{实}


disorders, and $13.5 \%$ had depression [18]. Breslau et al. found a greater than 4-fold risk of attempted suicide in migraineurs compared with controls who have never experienced headaches above mild intensity [18]. A longitudinal population based study shows that $30 \%$ of chronic migraine sufferers, and $19 \%$ of the patients with episodic migraine have anxiety [16]. Chronic stress is a widely recognized risk factor for both depression and chronic migraine [19]. It has been shown that psychological stress plays an important role not only before the onset of migraine [20,21], but also in the maintenance of the disorder, as well as the transformation from episodic to chronic migraine [22]. It is estimated that episodic migraine (EM) sufferers develop chronic migraine $(\mathrm{CM})$ at the rate of $2.5 \%$ per year [23]. Previous studies have demonstrated that, when compared to EM, CM is associated with greater disability and lower quality of life [24-27]. Several studies support the view that psychiatric comorbidities can promote the transformation of episodic headaches into chronic daily headache $[28,29]$. This transformation may increase headache related disability, as well as the difficulty of treating it [13].

Although studies have demonstrated the association between migraine and psychiatric disorders, less is known about the relationship between somatic amplification and migraine related disability. Barsky et al. first introduced the notion of somatosensory amplification [30-32]. It was hypothesized that individuals who somatize perceive normal bodily sensations as unusually intense and disturbing. We hypothesize that somatic amplification together with depression, anxiety and stress may increase the burden of migraine and increase the risk of migraine related disability. Thus psychiatric comorbidity should not be underestimated, but should be treated promptly.

The present study was designed to determine the relationship between migraine related disability and somatic amplification and to consider its association with anxiety, depression and stress levels. To the best of our knowledge this is the fist study to investigate the relationship between the perception of bodily sensations and disability in migraineurs.

\section{Method}

\section{Subjects}

Fifty-five of ninety-four consecutive migraine patients aged between 15 and 50 years who applied to the outpatient unit of the Neurology Department of Acibadem University School of Medicine, Maslak Hospital in Istanbul, Turkey between September 2012 and January 2013 were recruited for the study. Migraine diagnosis was conducted by two neurologists according to the International Classification of Headache Disorders, second edition (ICHD-II) [33]. Exclusion criteria were the recent use of antidepressant and psychotropic drugs ("recent use" was determined as 8 weeks or less before the study since all known antidepressants studied in clinical trials cause a clinical response in about twothirds of patients within 8 weeks of initiating treatment [34]), acute and chronic psychosis, mental retardation and illiteracy. Thirty-nine patients were excluded due to their recent use of psychotropic drugs or unwillingness to participate in the study. Twenty-eight healthy control subjects matched in age and sex were recruited at the same time. The control subjects did not meet the criteria for either migraine or non-migraine headache. Migraineurs were divided into two groups, CM and EM. To be classified as CM, a respondent had to report an average of 15 or more headache days per month within the past three months. EM was defined as reporting an average of 14 or fewer headache days per month within the past three months. In order to evaluate the sociodemographic and clinical characteristics of the participants, they were asked to answer a sociodemographic questionnaire. After they had been informed about the study and given written informed consent, the subjects were asked to fill out a Migraine Disability Assessment Scale (MIDAS), Depression Anxiety Stress Scale (DASS) and Somatosensory Amplification Scale (SSAS). All of the fifty five the subjects were found eligible and they all agreed to participate in the study. One patient with migraine did not fillout the migraine disability assessment scale.

The study protocol was conducted in accordance with the ethical principles stated in the "Declaration of Helsinki" and approved by the Ethical Committee of Acibadem University School of Medicine.

\section{Materials \\ Sociodemographic data form}

The sociodemographic form was developed by the investigators to evaluate sociodemographic characteristics such as age, sex, education status, marital status, occupational status and clinical characteristics.

\section{Migraine disabilty assessment scale}

The disability associated with migraine was assessed using the validated Turkish version of MIDAS. This has five questions assessing the number of working days lost due to migraine over a three month period. MIDAS gathers information on migraine related disability in terms of work/study, household work, and leisure activities on the days when the headache was experienced [35]. The questions are asked regarding either days of missed activity or days during which productivity was reduced by at least $50 \%$. The total days are summed and categorized into four grades of severity. The four point grading system for the MIDAS questionnaire is as 
follows: Grade I (scores ranging from 0 to 5), little or no disability; Grade II (scores ranging from 6 to 10), mild disability; Grade III (scores ranging from 11-20), moderate disability; Grade IV (scores of 21 or greater), severe disability. MIDAS A and MIDAS B assess headache frequency and pain intensity $(0=$ no pain; $10=$ very severe pain) over a three month period. The Turkish version of the MIDAS questionnaire was developed by Ertas et al. [36].

\section{Somatosensory amplification scale}

The Somatosensory Amplification Scale evaluates sensitivity to mild bodily sensations which are unpleasant and disturbing but non-pathological. This self-evaluating scale developed by Barsky et al. consists of 10 items that are estimated on a five-point scale ranging from 1 ('not at all') to 5 ('extremely') [31]. The statements describe a physical discomfort which does not indicate a disease. By summing up the scores a total amplification score is obtained. The reliability and validity of the Turkish form was established by Gulec et al. [37].

\section{Depression anxiety stress scale}

The Depression Anxiety Stress Scale was used in the present study for data collection to assess the negative emotional symptoms among participants. It is a 42 item self-report inventory designed by Lovibond et al. [38]. It provides scores on three subscales: depression (14 items), anxiety (14 items) and stress (14 items). Each item is rated on a four-point Likert scale showing the frequency or severity of the participants' experiences over the last week. This scale was validated to Turkish by Akin et al. [39].

\section{Statistical analyses}

Statistical analyses were performed using the Statistical Package for the Social Sciences (SPSS) version 13.0 (SPSS Inc., Chicago, IL., U.S.A, 2005) The data of categorical variables were demonstrated as counts and percentages. The data of continuous variables were presented as the mean and standard deviation. The Mann Whitney $\mathrm{U}$ test was used to compare the nonparametric variables. The correlations between the scales were tested using Pearson's Correlation Analysis. The level of statistical significance was set at $\mathrm{p}<0.05$.

\section{Results}

\section{Sociodemographic and clinical characteristics}

A total of 55 migraineurs answered the questionnaires in this study. Of the 55 patients, $42(76.4 \%)$ were female and $13(23.6 \%)$ were male. The mean age of the participants was $31.98 \pm 7.22$ (ranging between 15 and 47 ) years. $72.7 \%$ of the migraineurs were employed and $57.4 \%$ were married. Among the 55 migraineurs, 52 (94.5\%) had
Table 1 Sociodemographic and clinical characteristics of migraineurs $(\mathbf{n}=55)$

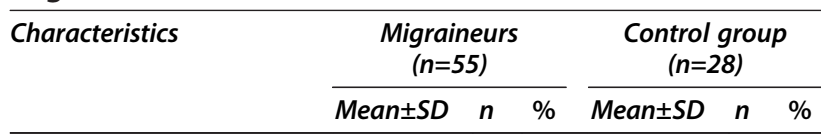

Sex

$\begin{array}{lllll}\text { Female } & 42 & 76.4 & 19 & 67.9\end{array}$

Male

$13 \quad 23.6$

$\begin{array}{ll}9 & 32.1\end{array}$

Age

$31.99 \pm 7.22$

$31.86 \pm 5.77$

Migrane and associated symptoms

With aura

35.5

Without aura

$52 \quad 94.5$

Episodic

$52 \quad 94.5$

Chronic

35.5

Duration of migraine (years)

Duration of attacks (days) $\quad 1.66 \pm 0.81$

Attacks per month $\quad 6.02 \pm 4.31$

Pain intensity (NAS) $\quad 7.35 \pm 1.31$

$\begin{array}{ll}40 & 72.7\end{array}$

Vomitting

$\begin{array}{ll}7 & 12.7\end{array}$

Photophobia

$43 \quad 78.2$

Phonophobia

$26 \quad 47.3$

Vertigo

$5 \quad 9.3$

Previous psychiatric history

None

Depression

$8 \quad 14.5$

Anxiety

23.6

SD Standart deviation, $\mathrm{n}=$ number of subject, NAS Numeric analogue scale.

migraine without aura, while the remaining 3 patients (5.5\%) had migraine with aura. The mean duration of migraine was $8.78 \pm 6.8$ years. $90.9 \%$ of the patients had accompanying symptoms such as photophobia, phonophobia, nausea and vomiting. Five of the 55 (9.3\%) patients had vertigo. The mean pain intensity of the patients was $7.35 \pm 1.31$ (numerical analogue scale, ranging between 0 and 10). The mean number of attacks for at least three consecutive months was $17.96 \pm 13.04$ days. The mean duration of attacks was $1.66 \pm 0.81$ days. Three patients $(5.5 \%)$ suffered from CM Table 1 shows the sociodemographic and clinical characteristics.

\section{Table 2 MIDAS grades of the migraineurs}

\begin{tabular}{lc}
\hline MIDAS grade & \% \\
\hline Grade I (little/no disability) $(\mathbf{n}=\mathbf{1 3})$ & 24.1 \\
Grade II (mild disability) $(\mathbf{n}=\mathbf{8})$ & 14.8 \\
Grade III (moderate disability) $(\mathbf{n}=\mathbf{1 6})$ & 29.6 \\
Grade IV (severe disability) $(\mathbf{n}=\mathbf{1 7})$ & 31.5 \\
\hline
\end{tabular}

$\mathrm{N}=$ number of subject, MIDAS: Migraine diability assessment scale. 
Table 3 Comparison of scores between minimal- mild disability group and moderate - severe disability group

\begin{tabular}{lccc}
\hline Scales & $\begin{array}{c}\text { Group I }(\mathbf{n}=\mathbf{2 1 )} \\
\text { (MIDAS I-II) } \\
\text { (Minimal-mild } \\
\text { disability) }\end{array}$ & $\begin{array}{c}\text { Group II (n=33) } \\
\text { (MIDAS III-IV) } \\
\text { (moderate-severe } \\
\text { disability) }\end{array}$ & P \\
\hline SSAS & $27.71 \pm 5.49$ & $31.7 \pm 6.4$ & $\mathbf{0 . 0 1}$ \\
DASS depression & $7.38 \pm 8.11$ & $11.27 \pm 8.7$ & $\mathbf{0 . 0 4}$ \\
DASS anxiety & $7.9 \pm 5.71$ & $11.67 \pm 7.95$ & 0.09 \\
DASS stress & $14.29 \pm 8.6$ & $17.94 \pm 7.84$ & 0.1
\end{tabular}

MIDAS Migraine disability assessment scale, SSAS Somatosensory amplification scale, DASS Depression anxiety stress scale, $\mathrm{n}=$ number of subject.

Association between migraine related disability, somatic amplification, depression, anxiety and stress levels

The MIDAS scores showed that 13 patients $(24.1 \%)$ had minimal disability, 8 (14.8\%) patients had mild disability, 16 (29.6\%) had moderate disability and 17 (31.5\%) had severe disability (Table 2). The total scores for the migraine disability assessment scale were significantly higher in female patients than in male patients $(38.6 \pm 6.03$ vs $7.01 \pm 1.94 ; \mathrm{p}=0.03)$. Somatosensory amplification scores and depression scores were significantly higher in migraineurs with moderate and severe disability than in patients with minimal and mild disability $(31.7 \pm 6.4$ vs $27.71 \pm 5.49 ; \mathrm{p}=0.01,11.27 \pm 8.7$ vs $7.38 \pm 8.11$; $\mathrm{p}=0.04$, respectively) (Table 3 ).

A significant positive correlation was found between the frequency of migraine attacks for at least three consecutive months (MIDAS A scores) and the SSAS scores $(\mathrm{r}=0.363, \mathrm{p}=0.007)$ in migraineurs. The level of stress and anxiety symptoms was significantly associated with the presence of somatic amplification. Our analysis showed significant correlations between the somatic amplification scores and the scores for anxiety $(r=0.413$, $\mathrm{p}=0.002)$ and stress $(\mathrm{r}=0.291, \mathrm{p}=0.03)$ (Table 4). The MIDAS total scores were also significantly correlated with the DASS depression subcale scores $(r=0.267$, $\mathrm{p}=0.04)$ and the DASS stress subscale scores $(\mathrm{r}=0,268$, $\mathrm{p}=0.05$ ) (Table 4).

According to the DASS scores $38.2 \%$ of the patients had depressive symptoms, $61.8 \%$ of them had anxiety symptoms and $52.7 \%$ of the patients had mild, moderate or severe stress levels. Table 5 shows the grading of DASS scores in the migraineurs.

Table 4 Correlation of DASS scores with MIDAS total scores and SSAS

\begin{tabular}{lccc}
\hline & $\begin{array}{c}\text { DASS } \\
\text { depression } \mathbf{~} \mathbf{p}\end{array}$ & $\begin{array}{c}\text { DASS } \\
\text { anxiety } \mathbf{~} \mathbf{p}\end{array}$ & $\begin{array}{c}\text { DASS } \\
\text { stress } \mathbf{r} \mathbf{p}\end{array}$ \\
\hline MIDAS total & $r=0.276 \mathbf{p}=\mathbf{0 . 0 4}$ & $r=0.165 p=0.23$ & $r=0.268 \mathbf{p}=\mathbf{0 . 0 5}$ \\
SSAS & $r=0.196 p=0.15$ & $r=0.413 \mathbf{p}=\mathbf{0 . 0 0 2}$ & $r=0.291 \mathbf{p}=\mathbf{0 . 0 3}$
\end{tabular}

DASS Depression anxiety stress scale, MIDAS Migraine disability assessment scale, SSAS Somatosensory amplification scale.
Table 5 Prevalence of depression, anxiety and stres levels according to DASS

\begin{tabular}{lccccc}
\hline $\begin{array}{l}\text { DASS } \\
\text { subscales }\end{array}$ & $\begin{array}{c}\text { Normal } \\
\mathbf{N}(\%)\end{array}$ & $\begin{array}{c}\text { Mild } \\
\mathbf{N}(\%)\end{array}$ & $\begin{array}{c}\text { Moderate } \\
\mathbf{N}(\%)\end{array}$ & $\begin{array}{c}\text { Severe } \\
\mathbf{N}(\%)\end{array}$ & $\begin{array}{c}\text { Extremely } \\
\text { severe } \mathbf{N}(\%)\end{array}$ \\
\hline Depression & $34(61.8)$ & $7(12.7)$ & $7(12.7)$ & $4(7.3)$ & $3(5.5)$ \\
Anxiety & $21(38.2)$ & $8(14.5)$ & $13(23.6)$ & $7(12.7)$ & $6(10.9)$ \\
Stress & $27(49.1)$ & $7(12.7)$ & $10(18.2)$ & $9(16.4)$ & $2(3.6)$ \\
\hline
\end{tabular}

$\mathrm{n}=$ number of subject, DASS Depression anxiety stress scale.

Depression, anxiety and stress levels were significantly higher in the migraine patients than in the healthy control subjects: the Depression subscale $(10.02 \pm 8.75$ vs $6.96 \pm 8.72 ; \mathrm{p}=0.03)$, the Anxiety Subscale $(10.24 \pm 7.28$ vs $6.96 \pm 8.72 ; \mathrm{p}=0.03)$ and the Stress Subscale $(16.51 \pm 8.2$ vs 12.61 $\pm 8.79 ; \mathrm{p}=0.02)$. Somatosensory amplification scores were significantly higher in the magraineurs than in the control group $(29.85 \pm 6.63$ vs $26.07 \pm 7.1 ; \mathrm{p}=0.027)$. Table 6 shows a comparison of the migraineurs' scores and those of the control subjects. We also found that the scores in SSAS $(36.0 \pm 4.0$ vs $29.5 \pm 6.6 ; \mathrm{p}=0.07)$, DASS depression (16.67 \pm 18.18 vs $9.63 \pm 8.1 ; \mathrm{p}=0.5)$, anxiety $(13.33 \pm 7.77$ vs $10.06 \pm 7.3 ; \mathrm{p}=0.4)$ and stress $(24.0 \pm 7.98$ vs $16.08 \pm 8.07 ; \mathrm{p}=0.08)$ scales in patients with $\mathrm{CM}$ were higher than in patients with EM.

\section{Discussion}

The present study investigated the association between migraine disability and somatic amplification in a sample of 55 migraineurs. It also evaluated the relationship between migraine disability and psychological distress.

Our findings show that migraineurs had a significantly higher than average tendency to be aware of bodily sensations. Somatic amplification scores were significantly higher in migraine patients than in control subjects. Our results also point out the role of somatic amplification in migraine related disability. According to our data migraineurs with moderate and severe migraine related disability have higher somatosensory amplification scores than the patients with minimal and mild disability. Moreover there was a significant positive correlation between the SSAS scores and the frequency of headache for the last three months. Patients who have an increased attention to unpleasant bodily sensations and the tendency to appraise vague somatic

Table 6 Comparison of scores between migraineurs and healthy control subjects

\begin{tabular}{lccc}
\hline Scales & $\begin{array}{c}\text { Migraineurs } \\
(\mathbf{n}=\mathbf{5 5}) \\
\text { Mean } \pm \text { SD }\end{array}$ & $\begin{array}{c}\text { Control group } \\
(\mathbf{n}=\mathbf{2 8}) \\
\text { Mean } \pm \text { SD }\end{array}$ & $\mathbf{P}$ \\
\hline SSAS & $29.85 \pm 6.63$ & $26.07 \pm 7.1$ & $\mathbf{0 . 0 2 7}$ \\
DASS-depression & $10.02 \pm 8.75$ & $6.96 \pm 8.72$ & $\mathbf{0 . 0 3}$ \\
DASS-anxiety & $10.24 \pm 7.28$ & $7.79 \pm 8.27$ & $\mathbf{0 . 0 3}$ \\
DASS-stress & $16.51 \pm 8.2$ & $12.61 \pm 8.79$ & $\mathbf{0 . 0 2}$
\end{tabular}

SSAS Somatosensory amplification scale, DASS Depression anxiety stress scale. 
sensations as abnormal or pathological have more migraine attacks which may lead to a lower quality of life.

Psychological distress is well kown to be associated with increased physical symptoms [40]. Similarly our findings showed significant correlations between somatic amplification and level of anxiety and stress. Maizels et al. revealed that the increased prevalence of somatic symptoms in headeache patients with psychiatric comorbidity is not suprising [41], and somatoform disorders were diagnosed in the range $6 \%-22 \%$ of patients with chronic daily headache $[42,43]$. Researchers have shown that depression and anxiety disorders are frequently reported in adults with migraine [8-17]. In this study $38.2 \%$ of the migraineurs suffered from depressive symptoms. Similarly previous studies showed that the incidence of depressive symptoms ranges from $17 \%$ to $42 \%$ [13-16]. Our data shows that $62 \%$ of the patients with migraine had anxiety symptoms. This finding was higher than the rates reported in studies from Italy (38.1\%) [44], China (38.1\%) [45] and the USA (51\%) [46].

Consistent with Jelinkski's study, [47] we found that migraine related disability was significantly correlated with the level of depressive symptoms. In our study the severity of stress was also significantly correlated with migraine related disability. Our finding supports the necessity of treatment for psychiatric disorders in migraine patients since migraine and psychological distress significantly reduce the quality of life [13] and lead to a worse prognosis, chronic disease and a reduced response to treatment [48]. It has been indicated that migraine comorbid with depession or anxiety causes higher medical costs than does migraine alone [49].

Psychological factors and vulnerability to bodily sensations may incease the burden of migraine. Some episodic migraine patients develop chronic migraine through a transformative process [23,50,51]. Chronic migraine accounts for approximately $50 \%$ of all chronic daily headaches in the general population [52]. Poplation-based studies have demonstrated that compared to EM, CM is associated with greater migraine-disability, reduced quality of life, increased medical and psychiatric comorbidities, increased risk of medication overuse $[16,23,50]$. Therefore as Yong et al. say early diagnosis and treatment for psychiatric comorbidiy are very important [45]. Yong et al. suggest that if comorbid depression is not recognized and treated effectively, succesful headache management is unlikely [45]. Thus clinicians should be alert to psychological stress and somatic amplification when evaluating migraine patients.

Among our findings, we point out that the timely assessing of somatic amplification and the evaluation of psychological status would prevent migraine from becoming chronic and turning into a headache from medication overuse. Thus this strategy would help improve the quality of life of in migraineurs.

\section{Conclusion}

Previous studies have examined the psychiatric comorbidity and somatic symptoms in migraine patients. To the best of our knowledge this is the first study to investigate the association between somatic amplification and migraine disability. However our study has some limitations. First, our sample size was small and this may prevent our results from being generalized. Moreover we evaluated psychological distress only by a self-reported questionnaire. Future studies with a large sample size and a detailed psychiatric evaluation are needed to investigate further the influence of somatic amplification and psychological distress in migraine related disability.

\section{Competing interests}

The authors declare that they have no competing interests.

\section{Authors' contributions}

BGY, EIA, PY, Cl participated in the study and drafted the manuscript. All authors read and approved the final manuscript.

\section{Author details}

'Department of Psychiatry, Acibadem University School of Medicine, Istanbul, Turkey. ${ }^{2}$ Department of Neurology, Acibadem University School of Medicine, Istanbul, Turkey.

Received: 5 April 2013 Accepted: 20 June 2013

Published: 25 June 2013

\section{References}

1. Tepper SJ, Dahlöf CG, Dowson A, Newman L, Mansbach H, Jones M (2004) Prevalence and diagnosis of migraine in patients consulting their physician with a complaint of headache:data from landmark study. Headache 44(9):856-864

2. Tulen JH, Stronks DL, Bussmann JB, Pepplinkhuizen L, Passchier J (2000) Towards an objective quantitative assessment of daily functioning in migraine: a feasibility study. Pain 86(1-2):139-149

3. Bigal ME, Fernandes LC, Moraes FA, Bordini CA, Speciali JG (2000) Migraine prevalence and impact in employees of the clinical hospital of the medical school of Ribeirao Preto-USP. Arq Neuropsiquiatr 58(2B):431-436

4. Stovner LJ, Hagen K, Jensen R, Katsarava Z, Lipton RB, Scher Al, Steiner TJ, Zwart JA (2007) The global burden of headache: a documentation of headache prevalence and disability worldwide. Cephalalgia 27:193-210

5. Zarifoglu M, Karli N, Taskapilioglu O (2008) Can ID migraine be used as a screening test for adolescent migraine? Cephalalgia 28(1):65-71

6. Buse DC, Silberstein SD, Manack AN, Papapetropoulos S, Lipton RB (2012) Psychiatric comorbidities of episodic and chronic migraine. J Neurol, Nov 7 [Epub ahead of print]

7. Lipton RB, Silberstein SD (1994) Why study the comorbidity of migraine? Neurology 44:4-5

8. Breslau N, Davis GC, Andreski P (1991) Migraine, psychiatric disorders, and suicide attempts: an epidemiologic study of young adults. Psychiatry Res $37: 11-23$

9. Merikangas KR, Angst J, Isler H (1990) Migraine and psychopathology. Results of the Zurich cohort study of young adults. Arch Gen Psychiatry 47:849-853

10. Hamelsky SW, Lipton RB (2006) Psychiatric comorbidity of migraine. Headache 46:1327-1333

11. Breslau N, Schultz LR, Stewart WF, Lipton RB, Lucia VC, Welch KM (2000) Headache and major depression: is the association specific to migraine? Neurology 54:308-313

12. Lipton RB, Hamelsky SW, Kolodner KB, Steiner TJ, Stewart WF (2000) Migraine, quality of life, and depression: a populationbased case-control study. Neurology 55:629-635

13. Jette N, Patten S, Williams J, Becker M, Wiebe S (2008) Comorbidity of migraine and psychiatric disorders- a national population-based study. Headache 48:501-516 
14. Molgat CV, Patten SB (2005) Comorbidity of major depression and migraine A Canadian population-based study. Can J Psychiatry 50:832-837

15. Tietjen GE, Peterlin BL, Brandes JL, Hafeez F, Hutchinson S, Martin VT (2007) Depression and anxiety: effect on the migraine-obesity relationship. Headache 47:866-875

16. Buse DC, Manack A, Serrano D, Turkel C, Lipton RB (2010) Sociodemographic and comorbidity profiles of chronic migraine and episodic migraine sufferers. J Neurol Neurosurg Psychiatry 81(4):428-432

17. Chen YC, Tang CH, Ng K, Wang SJ (2012) Comorbidity profiles of chronic migraine sufferers in a national database in Taiwan. J Headache Pain 13:311-319

18. Breslau N, Schultz L, Lipton R, Peterson E, Welch KM (2012) Migraine headaches and suicide attempt. Headache 52:723-731

19. Blackburn-Munro G, Blacburn-Munro RE (2001) 20019 Chronic pain, chronic stress and depression: coincidence or consequence? J Neuroendocrinol 13:1009-1023

20. Wöber C, Wöber-Bingöl C (2010) Triggers of migraine and tension-type headache. Handb Clin Neurol 97:161-172

21. Yadav RK, Kalita J, Misra UK (2010) A study of triggers of migraine in India, Pain Med 11:44-47

22. Bigal ME, Lipton RB (2009) What predicts the change from episodic to chronic migraine? Curr Opin Neurol 22:269-276

23. Bigal ME, Serrano D, Buse D, Scher A, Stewart WF, Lipton RB (2008) Acute migraine medications and evolution from episodic to chronic migraine: a longitudinal population-based study. Headache 48(8):1157-1168

24. Lante'ri-Minet M, Duru G, Mudge M, Cottrell S (2011) Quality of life impairment, disability and economic burden associated with chronic daily headache, focusing on chronic migraine with or without medication overuse: a systematic review. Cephalalgia 31(7):837-850

25. Wang SJ, Fuh JL, Lu SR, Juang KD (2001) Quality of life differs among headache diagnoses: analysis of SF-36 survey in 901 headache patients. Pain 89(2-3):285-292

26. Bigal ME, Serrano D, Reed M, Lipton RB (2008) Chronic migraine in the population: burden, diagnosis, and satisfaction with treatment. Neurology 71(8):559-566

27. Blumenfeld AM, Varon SF, Wilcox TK, Buse DC, Kawata AK, Manack A, Goadsby PJ, Lipton RB (2011) Disability, HRQoL and resource use among chronic and episodic migraineurs: results from the International Burden of Migraine Study (IBMS). Cephalalgia 31(3):301-315

28. Lipton RB, Pan J (2004) Is migraine a progressive brain disease? JAMA 291:493-494

29. Scher Al, Lipton RB, Stewart W (2002) Risk factors for chronic daily headache. Curr Pain Headache Rep 6:486-491

30. Barsky AJ, Goodson JD, Lane RS, Cleary PD (1988) The amplification of somatic symptoms. Psychosom Med 50:510-519

31. Barsky AJ, Wyshak G (1990) Hypochondriasis and somatosensory amplification. Br J Psychiatry 157:404-409

32. Barsky AJ, Wyshak G, Klerman GL (1990) The somatosensory amplification scale and its relation to hypochondriasis. J Psychiatr Res 24:323-334

33. Headache Classification Subcommittee of the International Headache Society (2004) The international classification of headache disorders: 2nd edition. Cephalgia 24(Suppl 1):9-160

34. Stahl SM (2008) Stahl's Essential Psychopharmacology Neuroscientific Basis and Practical Applications 3rd edn. Cambridge University Press, New York, USA

35. Stewart WF, Lipton RB, Dowson AJ, Sawyer J (2001) Development and teting of the migraine disability assessment (MIDAS) questionnaire to assess headache-related disability. Neurology 56(suppl 1):20-28

36. Turkish MIDAS group, Ertas M, Siva A, Dalkara T, Uzuner N, Dora B, Inan L, Idiman F, Sarica Y, Selcuki D, Sirin H, Oğuzhanoglu A, Irkec C, Ozmenoglu M, Ozbenli T, Ozturk M, Saip S, Neyal M, Zarifoglu M (2004) Validity and reliability of the Turkish Migraine Disability Assessment (MIDAS) questionnaire. Headache 44(8):786-793

37. Gulec H, Sayar K (2007) Reliability and validity of the Turkish form of the Somatosensory Amplification Scale. Psychiatry Clin Neurosci 61:25-30

38. Lovibond PF, Lovibond SH (1995) Manual for the Depression Anxiety Stress Scales, 2nd edn. Psychology Foundation, Sydney

39. Akin A, Cetin B (2007) The Depression Anxiety And Stress Scale (DASS): The study of validity and reliability. Educ Sci: Theory \& Practice 7(1):260-268

40. Katon WJ, Walker EA (1998) Medically unexplained symptoms in primary care. J Clin Psychiatry 59(suppl 20):15-21
41. Maizels M, Burchette R (2004) Somatic symptoms in headache patients: the influence of headache diagnosis, frequency, and comorbidity. Headache 44:983-993

42. Verri AP, Cecchini AP, Galli C, Graneelle F, Sandrini G, Nappi G (1998) Psychiatric comorbidity in chronic daily headache. Cephalgia 18(suppl 21):45-49

43. The Italian Collaborative Group fort he Study of Psychopathological Factors in Primary Headaches (1999) Psychiatric comorbidity and psychosocial stres in patients with tension-type headache from headache centers in Italy. Cephalgia 19:159-164

44. Beghi E, Bussone G, Amico DD, Cortelli P, Cevoli S, Manzoni GC (2010) Headache, anxiety and depressive disorders:the HADAS study. J Headache Pain 1:141-150

45. Yong N, Hu H, Fan X, Li X, Ran L, Qu Y, Wang Y, Tan G, Chen L, Zhou J (2012) Prevalence and risk factors for depression and anxiety among outpatient migraineurs in mainland China. J Headache Pain 13:303-310

46. Breslau N (1998) Psychiatry comorbidity in migraine. Cephalgia 18(suppl 22):56-61

47. CHORD Study Group, Jelinski SE, Magnusson JE, Becker WJ (2007) Factors associated with depression in patients referred to headache specialists. Neurology 68:489-495

48. Pompili $\mathrm{M}$, Cosimo DD, Innamorati $\mathrm{M}$, Lester $\mathrm{D}$, Tatarelli $\mathrm{R}$, Marteletti $\mathrm{P}$ (2009) Psychiatric comorbidity in patients with chronic daily headache and migraine: a selective overwiev including personality traits and suicide risk. J Headache Pain 10(4):283-290

49. Pesa J, Lage MJ (2004) The medical costs of migraine and comorbid anxiety and depression. Headache 44:562-570

50. Suh GI, Park JW, Shin HE (2012) Differences in clinical features and disability according to the frequency of medication use in patients with chronic migraine. J Clin Neurol 8:198-203

51. Ashina S, Serrano D, Lipton RB, Maizels M, Manack AN, Turkel C, Reed ML, Buse DC (2012) Depression and risk of transformation of episodic to chronic migraine. J Headache Pain 13:615-624

52. Castillo J, Munez P, Pascual J (1999) Epidemiology of chronic daily headache in the general population. Headache 39:190-196

doi:10.1186/1129-2377-14-53

Cite this article as: Yavuz et al: Association between somatic amplification, anxiety, depression, stress and migraine. The Journal of Headache and Pain 2013 14:53.

\section{Submit your manuscript to a SpringerOpen ${ }^{\odot}$ journal and benefit from:}

- Convenient online submission

- Rigorous peer review

- Immediate publication on acceptance

- Open access: articles freely available online

High visibility within the field

- Retaining the copyright to your article

Submit your next manuscript at $>$ springeropen.com 